\title{
Breast cancer care during the coronavirus pandemic
}

\author{
Gil Facina ${ }^{1 *}$ (), Vilmar Marques de Oliveira1 (1)
}

The coronavirus disease 2019 (COVID-19) is caused by the virus SARS-CoV-2, a new coronavirus detected in December 2019 in Wuhan, China. ${ }^{1}$ Due to its highly contagious nature, the disease quickly spread over the world, and, on March 11, 2020, the World Health Organization declared the infection outbreak as the first pandemic caused by a coronavirus. ${ }^{2}$ On April 17, 2020, COVID-19 had reached 210 countries, infected over 2.2 million people, and caused more than 150 thousand deaths. ${ }^{3}$ Most infected individuals develop mild to moderate respiratory symptoms; however, older adults or those with health conditions, such as diabetes mellitus, cardiovascular disease, hypertension, chronic respiratory disease, chronic kidney disease, and immunodepression, may present severe forms of COVID-19 and require intensive medical care, with hospitalization and clinical and ventilatory support. It is worth mentioning that cancer patients are more susceptible to infections, either by the immunosuppressed state inherent to the disease or the necessary antiblastic treatment, such as chemotherapy, targeted therapy, and immunotherapy. ${ }^{1}$

In order to preserve and provide essential resources to fight the pandemic, public and private hospital services are forced to reduce the supply for routine care. Thus, patients and physicians must adapt to this new reality, seek protection against contamination in the work environment, and understand that the number of beds available for elective hospitalizations and emergency treatments is low. In addition, the cancer patient faces a higher risk of contamination by the new coronavirus in a saturated hospital environment. Yu et al. reviewed data from 1,525 cancer patients treated at a tertiary hospital in Wuhan, comparing the incidence of COVID-19 in these individuals with that of the general local population, and noted that the risk of infection by SARS-CoV-2 was significantly greater among the first group (odds ratio - OR=2.31; 95\% confidence interval - 95\%CI 1.89-3.02). ${ }^{4}$

In recent weeks, much has been discussed about adjustments to the care of cancer patients not infected by the new coronavirus during the pandemic to minimize the risk of contamination, without compromising the outcome of the disease. Some associations summarized recommendations that should be periodically adapted, given the rapid dissemination of COVID-19 and the local availability of resources., ${ }^{4,5}$

\section{RECOMMENDATIONS FOR THE CARE OF BREAST CANCER PATIENTS DURING THE COVID-19 PANDEMIC}

- Adopt the use of telemedicine (Office Letter from the Federal Council of Medicine no. 1,756/2020, March 19, 2020) on an exceptional basis during the fight against the COVID-19 for the remote instruction of patients in isolation, medical supervision of health parameters and/or disease, and exchange of information and opinions among physicians; ${ }^{6}$

- Schedule appointments with greater interval to reduce the contact between individuals in the waiting room;

- Decrease the number of companions in appointments;

- Keep a safe distance between the patient and health professionals;

- Do not make greeting gestures;

- Wash and sanitize the hands before and after the physical examination;

- Always use disposable gloves during the physical examination;

- Inform the patient about the signs and symptoms of COVID-19;

- Counsel the patient on social distancing and day-to-day hygiene;

- Offer the diagnostic test for the symptomatic patient;

- Postpone elective surgeries when possible. The decision should be individualized, based on common sense, multidisciplinary, and shared with the patient. The surgeries indicated must respect the hospital resources available, depending on the phase of the pandemic. In the initial phase (phase I) of the COVID-19 pandemic in a region, the hospital resources are still reasonable. Thus, patients who would have their survival impaired if not operated within the next three months should undergo surgery. Patients who have non-urgent surgeries postponed should be informed that the decisions was made by consensus and based on local resources, due to the prevalence of COVID-19, as well as the characteristics 
of the tumor and the expected results related to the delay. All information and instructions must be included in the medical records. In the next phase (phase II), hospital resources are scarce, with a limited number of respirators and intensive care unit beds. Surgeries are restricted to patients who would not survive a few days if not operated. Among these conditions, abscess drainage, hematomas, and review of flap ischemia (reconstructions with autologous flaps must not be performed) stand out. In phase III, no respirators or beds are available for admission. Virtually all hospital resources are consumed. At this stage, the surgeries are restricted to patients who would not survive a few hours if not operated;
- Postpone, discontinue, or modify the radiotherapy, when possible, depending on the risk of contamination and the clinical indication;

- Individualize the systemic therapy, grounding the measure in the likelihood of recurrence. Some patients can receive home infusions or change intravenous for oral therapy to reduce the number of visits to hospital units.

In short, the pandemic caused by the new coronavirus SARS-CoV-2 has an uncertain trajectory and represents a great challenge both economically and emotionally. ${ }^{7}$ It is the moment to learn and prepare for the huge impact that this outbreak might have on the appropriate support to cancer patients.

\section{REFERENCES}

1. Shankar A, Saini D, Roy S, Mosavi Jarrahi A, Chakraborty A, Bharti SJ, et al. Cancer Care Delivery Challenges Amidst Coronavirus Disease - 19 (COVID-19) Outbreak: Specific Precautions for Cancer Patients and Cancer Care Providers to Prevent Spread. Asian Pac J Cancer Prev. 2020;21(3):569-73. https://doi.org/10.31557/APJCP.2020.21.3.569

2. World Health Organization. WHO Director-General's opening remarks at the media briefing on COVID-19 [Internet]. World Health Organization; 2020 [acessado em 2 abr. 2020]. Disponível em: https://www.who.int/dg/speeches/detail/ who-director-general-s-opening-remarks-at-the-mediabriefing-on-covid-19---11-march-2020

3. Worldometers. COVID-19 coronavirus pandemic [Internet]. Worldometers; 2020 [acessado em 2 abr. 2020]. Disponível em: https://www.worldometers.info/coronavirus/

4. Yu J, Ouyang W, Chua MLK, Xie C. SARS-CoV-2 Transmission in Patients With Cancer at a Tertiary Care Hospital in Wuhan,
China. JAMA Oncol. 2020:e200980. https://dx.doi.org/10.1001 \%2Fjamaoncol.2020.0980

5. American College of Surgeons. COVID-19 Guidelines for Triage of Breast Cancer Patients. American College of Surgeons; 2020 [acessado em 2 abr. 2020]. Disponível em: https://www.facs.org/covid-19/clinical-guidance/electivecase/breast-cancer

6. Conselho Federal de Medicina. Ofício CFM no 1756/2020 COJUR. Conselho Federal de Medicina; 2020 [acessado em 3 abr. 2020]. Disponível em: http://portal.cfm.org.br/images/ PDF/2020_oficio_telemedicina.pdf

7. Ueda M, Martins R, Hendrie PC, McDonnell T, Crews JR, Wong TL, et al. Managing Cancer Care During the COVID-19 Pandemic: Agility and Collaboration Toward a Common Goal. J Natl Compr Canc Netw. 2020:1-4. https://doi.org/10.6004/ jnccn.2020.7560 